TURISMO ENOLÓgICO Y RUTA DEL VINO... del Río, R; Álvarez, G; Vila, A; Iglesias, G.

\title{
TURISMO ENOLÓGICO Y RUTA DEL VINO DEL BIERZO
}

del Río Rama, María de la Cruz ${ }^{1}$

Universidad de Vigo delrio@uvigo.es

Álvarez García, José ${ }^{2}$ Universidad de Extremadura pepealvarez@unex.es

Vila Alonso, Mercedes ${ }^{3}$

Universidad de Vigo mvila@uvigo.es

Iglesias González, Lorena ${ }^{4}$ Universidad de Vigo liglesias@masterturismoourense.es.

Material original autorizado para su primera publicación en la revista académica REDMARKA. Revista Digital de Marketing Aplicado.

https://doi.org/10.17979/redma.2013.01.011.4813

Recibido: 14 Octubre 2013

Aceptado 15 Diciembre 2013

${ }^{1}$ Doctora en Gestión y Dirección de Empresas (Universidad de Vigo). Profesora e Investigadora del Departamento de Organización de Empresas y Marketing de la Universidade de Vigo-Campus de Ourense.

2 Doctor en Dirección y Planificación de Turismo (Universidad de Vigo). Profesor e Investigador del Departamento de Economía Financiera y Contabilidad de la Universidad de Extremadura

${ }^{3}$ Doctora en Administración de Empresas (Universidad de Vigo). Profesora e Investigadora del Departamento de Organización de Empresas y Marketing de la Universidade de Vigo.

${ }^{4}$ Graduada en Administración de Empresas y Posgraduada en el Máster de Turismo de Interior y de Salud por la Universidad de Vigo- Campus de Ourense

REDMARKA UIMA-Universidad de A Coruña - CIECID

Año VI, Número 11, (2013), v2 pp. 185-212

http://www.redmarka.org/

ISSN 1852-2300 
TURISMO ENOLÓgico y RUTA DEL VINO... del Río, R; Álvarez, G; Vila, A; Iglesias, G.

\section{Resumen}

En este trabajo se exponen los resultados de un estudio empírico llevado a cabo en los establecimientos adheridos a la Ruta del Vino del Bierzo en el año 2013. Los objetivos que nos hemos planteado para la realización de este trabajo son: conocer el perfil de los establecimientos, la oferta de las actividades enoturísticas, así como, analizar el perfil de los enoturistas desde el punto de vista de los establecimientos, medir el nivel de satisfacción de su adhesión a la ruta, la imagen percibida del destino y su valoración de la actividad enoturística de la Ruta. Para finalizar, realizamos un análisis DAFO a partir de la información proporcionada por los establecimientos encuestados. La metodología consiste en un análisis descriptivo. Los resultados obtenidos nos han permitido dar respuesta a todos los objetivos planteados, manifestando el $42,42 \%$ de los establecimientos encuestados estar satisfechos y el $51,51 \%$ no estar ni satisfechos/ni insatisfechos con su adhesión. La valoración global media de la actividad enoturística de la Ruta es de 3,24 en una escala likert de cinco puntos.

Palabras clave: Enoturismo, Ruta del Vino Bierzo, Oferta, DAFO

\section{WINE TOURISM AND BIERZO WINE ROUTE}

\section{Abstract}

This paper presents the results of an empirical study carried out in the member establishments (wineries, restaurants and hotel accommodations) to Bierzo Wine Route in 2013. The objectives we have set for the realization of this work are: to know the profile of establishments, the offer of wine tourism activities, well as analyze the profile of enotourists from the point of view of the establishments, measure the level of satisfaction of their accession to the route, the perceived image of the destination and their assessment the perceived image of the destination and their assessment of the activity enoturística of Route. To finish, we conducted a SWOT analysis from the information provided by the establishments surveyed. The REDMARKA UIMA-Universidad de A Coruña - CIECID

Año VI, Número 11, (2013), v2 pp. 185-212

http://www.redmarka.org/

ISSN 1852-2300 
TURISMO ENOLÓgico y RUTA DEL VINO... del Río, R; Álvarez, G; Vila, A; Iglesias, G.

methodology consists of a descriptive analysis. The results obtained have enabled us responding to all the objectives manifesting $42.42 \%$ of establishments surveyed to be satisfied and $51.51 \%$ being neither satisfied / not satisfied with their adhesion.a The global assessment thirty in the of the Route enoturística activity of 3.24 into a fivepoint Likert scale.

Key words: Enotourism, Bierzo Wine Route, Offer, SWOT

\section{1.- INTRODUCCIÓN}

Los cambios acaecidos en la última década en lo que se refiere a temas de turismo; turistas cada vez más informados, exigentes y sofisticados que realizan salidas más cortas y numerosas a lo largo del año en busca nuevas experiencias que satisfagan sus actuales necesidades, más atractivas, originales y variadas (Rodríguez et al., 2010; Álvarez et al., 2012), están haciendo posible que aparezcan nuevos destinos diferentes a los tradicionales de sol y playa. Fruto de estas nuevas vertientes surgen las rutas turísticas del vino; existiendo una vinculación perfecta entre vino y turismo con la finalidad de que esta unión permita un mayor desarrollo socio-económico de las regiones vitivinícolas.

El turismo del vino, como modelo de desarrollo económico sostenible de ciertas áreas, es capaz de dinamizar en un único territorio la competencia, así como de incrementar la producción vinícola a la vez que mejorarla, y siempre respetando el medio ambiente y mejorando las condiciones de vida de los habitantes de dicha región. El enoturismo como actividad en sí misma, aporta a la industria vitivinícola la capacidad de mejorar las relaciones con los consumidores, así como, garantizar la posibilidad de conseguir más consumidores potenciales, tratando de buscar experiencias relacionadas con el mundo del vino y con sus territorios. De esta manera el enoturismo tiene el gran potencial de dar a conocer territorios donde se

REDMARKA UIMA-Universidad de A Coruña - CIECID

Año VI, Número 11, (2013), v2 pp. 185-212

http://www.redmarka.org/

ISSN 1852-2300 
TURISMO ENOLÓgico y RUTA DEL VINO... del Río, R; Álvarez, G; Vila, A; Iglesias, G.

llega a producir vino y al mismo tiempo de mejorar el rendimiento de las bodegas, así como el de los diferentes productos comercializados.

Recientes estudios en torno al turismo del vino sugieren y promueven la idea conjunta de que gastronomía y vino pueden ser y a menudo lo son, el principal motivo para visitar una región sin que simplemente se convierta en una actividad complementaria al viaje (Rodríguez G. et al. 2010, p. 52). Las visitas de enoturistas a bodegas contribuyen de una forma atractiva a la trasmisión de la propia cultura del vino, ya que no es necesario que dichos turistas tengan un conocimiento previo o profundo sobre los vinos, sino que simplemente les basta con seguir unos simples consejos para poder ponerlos en práctica antes, durante y después de la visita (Matellanes, 2009, p.1-2). Para que el enoturismo se convierta en una de las piezas fundamentales del turismo, es necesario continuar con las prácticas que se han llevado hasta el momento, tratando así de desarrollar un negocio de éxito y con posibilidades futuras.

El proyecto Rutas del Vino de España nace en el año 2001, cuando ACEVIN con el apoyo de la Secretaría General de Turismo inicia la definición y desarrollo de las normas de regulación de la calidad de este producto turístico. En sí, las Rutas del Vino de España son como indica Miranda y Fernández (2011, p.148-149) un "producto turístico basado en la integración de actividades vitícolas, gastronómicas, culturales y de ocio, acompañado por una amplia oferta de alojamiento, servicios relacionados con dicha actividad y otros complementarios, dentro de una misma zona vitivinícola. En todos los casos, el denominador común es uno: el vino". En la actualidad disponemos de un Club de Producto turístico integrado por 21 Rutas del Vino, 17 de las cuales están certificadas conforme a la Marca Rutas del Vino de España.

El objetivo principal de esta investigación es realizar un análisis de la Ruta del Vino del Ribeiro desde el punto de vista de su oferta enoturística, bodegas, restaurantes y alojamientos hoteleros adheridos a la ruta. Planteando como objetivos parciales: (1)

REDMARKA UIMA-Universidad de A Coruña - CIECID

Año VI, Número 11, (2013), v2 pp. 185-212

http://www.redmarka.org/

ISSN 1852-2300 
TURISMO ENOLÓgico y RUTA DEL VINO... del Río, R; Álvarez, G; Vila, A; Iglesias, G.

conocer el perfil de de los establecimientos objeto de estudio, (2) su oferta de actividades enoturísticas, (3) analizar el perfil de los enoturistas desde el punto de vista de los establecimientos, (4) medir el nivel de satisfacción de su adhesión, (5) la imagen percibida del destino y (6) y su valoración de la actividad enoturística de la Ruta. Para finalizar (7), realizamos un análisis DAFO a partir de la información proporcionada por los establecimientos encuestados.

Con la finalidad de alcanzar los objetivos que nos hemos planteado estructuramos el trabajo en varios apartados. En primer lugar planteamos el marco teórico derivado de la revisión bibliográfica efectuada: marco conceptual del Enoturismo en España, explicando detalladamente lo que es el enoturismo y sus puntos de desarrollo, así como, efectuamos una explicación conceptual de que es una ruta del vino, y para finalizar el apartado se realiza una descripción del área geográfica objeto de estudio; "Ruta del Vino en el Bierzo". Los dos siguientes apartados se destinan a la investigación empírica de la oferta del Vino en el Bierzo; descripción de la metodología empleada y la presentación del análisis de datos realizado. Finalmente en el último apartado se recogen las principales conclusiones obtenidas en la investigación así como las futuras líneas de investigación.

\section{2.- Marco conceptual del enoturismo y rutas del vino}

\subsection{Enoturismo}

El turismo del vino ${ }^{5}$ en es el culmen de dos conceptos, recurso y servicio turístico, ambos de especial interés según las zonas vinícolas. La definición del término enoturismo no es uniforme, ya que se puede analizar desde diferentes ópticas, como la del marketing o la de la motivación. Por ello, y basándonos en Getz y Brown (2006) en López, T. et al (2008, p.161), "el enoturismo es simultáneamente un comportamiento del consumidor, una estrategia para desarrollar el área geográfica y

\footnotetext{
${ }^{5}$ Vachiano, M. y Ramón, J. (2013) realizan una revisión de la literatura académica existente sobre el turismo enológico.
}

REDMARKA UIMA-Universidad de A Coruña - CIECID

Año VI, Número 11, (2013), v2 pp. 185-212

http://www.redmarka.org/

ISSN 1852-2300 
TURISMO ENOLÓgico y RUTA DEL VINO... del Río, R; Álvarez, G; Vila, A; Iglesias, G.

el mercado del vino de dicha zona, y una oportunidad de promoción de las bodegas para vender sus productos a los consumidores", siendo seis los ejes principales para dar forma a la actividad enoturistica; autenticidad, sostenibilidad, competitividad, territorio, cultura del vino y turismo (Recevin, 2006, p.5).

El vino, hoy en día, es un producto emergente, alrededor del cual surgen otras actividades complementarias (orientadas a que el cliente permanezca más tiempo en la zona y tenga mayor variedad de oferta turística), que permiten satisfacer las necesidades de conocimiento, ocio y disfrute de nuevas experiencias por ello el enoturismo es un sector en auge, dinamizador de la economía, desestacionalizador de la demanda, creador de empleo, y herramienta clave para evitar el despoblamiento del rural.

\subsection{Rutas del Vino}

Una ruta del vino la podemos definir como la utilización de todos los recursos y servicios turísticos que existen en una determinada zona vinícola, con el principal objetivo de crear un producto turístico propio, adecuándolo al destino, para que favorezca el desarrollo económico y social de un determinado territorio.

La Asociación Española de Ciudades del Vino (ACEVIN) ${ }^{6}$, define "Las Rutas del Vino de España como un producto turístico innovador, temático, cultural, gastronómico y de interior. Se basa en la integración de los recursos y servicios turísticos de interés de una zona vinícola, planteados desde la autenticidad y la vocación vivencial. Es un producto que se asienta sobre una estrategia de desarrollo socioeconómico integral del territorio, de cooperación público-privada y de valoración de la identidad y cultura vitivinícola del destino" (ACEVIN, 2001). La ventaja principal de la adhesión a una Ruta del vino, es que el conjunto de todos los elementos pertenecientes a la ruta

\footnotetext{
${ }^{6}$ ACEVIN: La Asociación Española de Ciudades del Vino (ACEVIN) fue creada en 1994. Presidida por el Ayuntamiento de Alcázar de San Juan, agrupa a más de 70 ciudades de todo el territorio nacional que tienen como denominador común la gran importancia del vino en su economía, cultura, patrimonio y desarrollo. La misión de ACEVIN es la de valorizar el potencial de estas zonas derivado del mundo del vino y utilizarlo como motor de otras actividades (http://www.acevin.es/).
}

REDMARKA UIMA-Universidad de A Coruña - CIECID

Año VI, Número 11, (2013), v2 pp. 185-212

http://www.redmarka.org/

ISSN 1852-2300 
TURISMO ENOLÓgICO Y RUTA dEL VINO... del Río, R; Álvarez, G; Vila, A; Iglesias, G.

tendrá una mayor capacidad de atracción que la mayoría de los integrantes de manera individual.

Las Rutas del vino son un producto del turismo rural y que se caracterizan por encontrarse correctamente organizados y elaborados, además de que en cada una de ellas podremos encontrar una gran cantidad de atractivos, como pueden ser, las actividades instalaciones y los servicios turísticos de cada territorio. Por ello es necesario clasificar a dichas rutas como un macro producto con sus propias características, que según DTS Consultores (2007, p.12) son: dar respuesta a una imagen motivadora, atractiva y particular; se escribe a un espacio geográfico concreto correctamente definido, a una determinada cultura y a una comunidad; disponer de una extensión espacio-temporal posible de recorrer en los plazos razonables y entre los tiempos mínimos y máximos establecidos; la visita debe ser factible parcialmente o íntegramente; debe disponer de diferentes productos y servicios.

Desde la creación de la Asociación Española de Ciudades del Vino (ACEVIN) en el año 1994, se ha trabajado para desarrollar nuevas rutas del vino en diferentes territorios, pero siempre bajo unas normas que permitan el crecimiento y desarrollo armonizado de este producto, para su posterior promoción dentro y fuera del territorio nacional. En España disponemos en la actualidad de 21 Rutas, de las cuales cuatro se encuentran en proceso de certificación (Rutas del Vino de España, 2012).

Cada ruta certificada ${ }^{7}$, está vinculada a una Denominación de Origen $^{8}$ (D.O.). En Castilla y León existen cinco Denominaciones de Origen, de las cuales sólo cuentan

\footnotetext{
${ }^{7}$ Según ACEVIN "Ruta del Vino certificada es la que acredita periódicamente el cumplimiento de los criterios de calidad establecidos en el Manual de Producto Turístico Rutas del Vino de España, en el que también se indica la metodología para su implantación y posterior certificación por parte del Comité de Gestión y Certificación de las Rutas del Vino de España. En este manual se definen un conjunto de requisitos aplicables a la entidad gestora de la ruta, tales como el sistema de gestión de la misma, la señalización, las acciones de promoción y apoyo a la comercialización, así como los relativos a las distintas tipologías de establecimientos que pueden formar parte de ella: restaurantes, alojamientos, bodegas, comercios, etc. Por tanto, la marca Rutas del Vino de España establece unos criterios de calidad y diferencia a estas rutas frente a otras propuestas enoturísticas, lo cual proporciona confianza a quien las elige". http://www.acevin.es/.
}

REDMARKA UIMA-Universidad de A Coruña - CIECID

Año VI, Número 11, (2013), v2 pp. 185-212

http://www.redmarka.org/

ISSN 1852-2300 
TURISMO ENOLÓgICO Y RUTA DEL VINO... del Río, R; Álvarez, G; Vila, A; Iglesias, G.

con una Ruta del Vino asociada, dos según ACEVIN; Ruta del vino Enoturismo en el Bierzo y Ruta del Vino Ribera del Duero.

\subsection{Ruta del vino en el Bierzo "Enoturismo Bierzo"}

En los años sesenta surgió un movimiento cooperativo en el Bierzo en la producción de vinos, reconocido como tal en 1.989, cuando el Ministerio de Agricultura, Pesca y Alimentación les concedió la Denominación de Origen a los vinos del Bierzo. Desde entonces han trabajado en consonancia para idear una Ruta que unificara todos los productos característicos de la zona y así en diciembre de 2011 la Ruta del Vino Enoturismo en el Bierzo es certificada por la Asociación Española de Ciudades del Vino (ACEVIN).

Esta ruta nace, con el objetivo de reagrupar todas las opciones turísticas que ofrece la comarca en torno al mundo del vino, tanto en hoteles, bodegas restaurantes, museos, vinotecas, como cualquier otro establecimiento que esté relacionado con el mundo del vino. En ella podemos descubrir los secretos de la cata y nos permiten adentrarnos en sus bodegas y viñedos, donde nos muestran cómo se elabora el vino, un vino muy peculiar por las características que le ofrece tanto su situación geográfica, como su terreno y su clima. Por eso, nos proponen un recorrido por las villas y pueblos de la ruta.

La Ruta del Vino del Bierzo está situada al Noroeste de la Provincia de León, atravesada por la vía del Noroeste (A-6) de este a oeste y sirviendo de enlace entre Madrid y Galicia y es un ente mixto formado por 64 entidades públicas y privadas. Entre las empresas podemos distinguir las enológicas (bodegas, vinotecas, bares de vinos, comercios especializados y enotecas) y las empresas turísticas (alojamientos, restaurantes, agencias de viajes, museos y empresas de ocio). Concretamente el

\footnotetext{
${ }^{8}$ Pero para poder entender el concepto de Denominación de Origen debemos acudir a la definición proporcionada por el Ministerio de Agricultura, Alimentación y Medio Ambiente del Gobierno de España en su página web http://www.magrama.gob.es/es/alimentacion/temas/calidad-agroalimentaria/calidad-diferenciada/dop/htm/informacion.aspx y Tallarico (2000: párr.13-14) "Aquella región, comarca o lugar reconocido administrativamente para designar a vinos que cumplan los siguientes requisitos: producir vinos a partir de materias primas de las zonas registradas, disfrutar de prestigio comercial, contar con calidad y características exclusivas al medio geográfico y haber transcurrido 5 años desde su reconocimiento como vino de calidad con indicación geográfica".
}

REDMARKA UIMA-Universidad de A Coruña - CIECID

Año VI, Número 11, (2013), v2 pp. 185-212

http://www.redmarka.org/

ISSN 1852-2300 
TURISMO ENOLÓgICO Y RUTA dEL VINO... del Río, R; Álvarez, G; Vila, A; Iglesias, G.

visitante puede disfrutar de 17 entidades enológicas (bodegas y bares de vinos), 26 establecimientos de alojamiento y/o restauración, 1 agencia de viajes, 1 museo y 1 empresas de ocio, 3 comercios especializados y 1 enoteca. Además cuenta con el apoyo de 13 entes públicos, los 12 ayuntamientos por los que transcurre la Ruta Enoturismo Bierzo y el Consejo Regulador de la Denominación de Origen Bierzo.

En la tabla 2 se recogen las principales características y datos técnicos de la Ruta del Vino Enoturismo en el Bierzo.

Tabla 2: Ruta del Vino Enoturismo en el Bierzo

\begin{tabular}{|c|c|c|c|}
\hline & \multicolumn{3}{|c|}{ RUTA DEL VINO ENOTURISMO EN BIERZO } \\
\hline 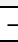 & Localización: Noroeste de la prov & León. & \\
\hline- & Extensión: 3.000 ha. & & \\
\hline- & $\begin{aligned} \text { Variedades de uva: } \\
\text { - } \quad \text { BLANCAS: Doña Blanc } \\
\text { TINTAS: Mencía y Garn }\end{aligned}$ & lo, Malvasía, Palomino. & \\
\hline- & $\begin{aligned} & \text { Establecimientos de la ruta: } \mathbf{5 1 .} \\
& \text { - } \text { Rodegas: } 12 . \\
& \text { - } \text { Alojamientes: } 9 . \\
& \text { - } 17 . \\
& \text { Vinotecas: } 1 .\end{aligned}$ & $\begin{array}{ll} & \text { Museos: } 2 . \\
\text { - } & \text { Bar de Vinos: } 1 . \\
& \text { eomercios } \\
& \text { especializados: } 3 .\end{array}$ & $\begin{array}{l}\text { - Agencias de Viajes: } 1 . \\
\text { - Oficinas de turismo: } 4 . \\
\text { - Ocio Complementario: } 1 .\end{array}$ \\
\hline- & $\begin{array}{c}\text { Municipios de la ruta: } 12 . \\
\text { Arganza. } \\
\text { - } \text { Cacabibre. } \\
\text { - } \\
\text { camponaraya. }\end{array}$ & $\begin{array}{l}\text { - } \text { Congosto. } \\
\text { - } \text { Cubillos del Sil. } \\
\text { - } \text { Molinaseca. } \\
\text { - }\end{array}$ & $\begin{array}{l}\text { Toral de los Vados. } \\
\text { - Vega de Espinareda. } \\
\text { Villafranca del Bierzo. }\end{array}$ \\
\hline
\end{tabular}

Mezcla entre la gastronomía tradicional y la moderna. El más famoso de sus productos, es el Botillo del Bierzo, bajo la regulación del Consejo Regulador de la Indicación Geográfica Protegida. La Cofradía Gastronómica del Real Botillo del Bierzo celebra numerosas fiestas promocionales de este producto, denominadas popularmente "Botilladas".

Además, de otros manjares como la manzana reineta, la pera conferencia, el pimiento del Bierzo, cerezas, guindas, miel y nueces. Por último, la castaña, centenaria por esta zona, se acredita como una de las mejores gracias a su Marca de Garantía, sello de calidad de origen.

- Patrimonio:

Las Médulas, declaradas Patrimonio de la Humanidad, son un paisaje cultural resultado de la intervención romana en la zona. La Tebaida Berciana, los montes Aquilianos, el valle de Fornela, el valle del Sil o la sierra de Gistredo. Existen también espacios protegidos como la sierra de Los Ancares, declarada Reserva de la Biosfera por la UNESCO. Mencionar también los 12 Bienes de Interés Cultural y el paso del Camino de Santiago, Patrimonio de la Humanidad.

Fuente: Elaboración propia a partir de la información de las páginas Rutas del Vino de España, y Enoturismo en el Bierzo (12/05/2013)

\section{3.- METODOLOGÍA DE INVESTIGACIÓN}

La investigación se ha desarrollado en tres fases:

REDMARKA UIMA-Universidad de A Coruña - CIECID

Año VI, Número 11, (2013), v2 pp. 185-212

http://www.redmarka.org/

ISSN 1852-2300 
TURISMO ENOLÓgICO Y RUTA dEL VINO... del Río, R; Álvarez, G; Vila, A; Iglesias, G.

(1) Confección de la base de datos y elaboración de los cuestionarios: la base de datos quedó constituida por los establecimientos (bodegas, restaurantes y alojamientos) adheridos a la Ruta del Vino en el Bierzo (Comunidad Autónoma de Castilla y León), obtenida a partir de la página web Enoturismo Bierzo (http://www.enoturismoenelbierzo. com/). Así la población objeto de estudio se compone de 15 bodegas, 16 alojamientos y 8 restaurantes. Se elaboraron tres cuestionarios diferenciados para cada uno de los establecimientos a partir de la información obtenida de la revisión bibliográfica previa realizada sobre estudios que realizan análisis similares en otras Rutas del Vino. Por tanto, nos hemos apoyado para la elaboración de los cuestionarios en la Guía de Sostenibilidad para empresas del sector enoturístico (ACEVIN, 2010, p.31-295); Estudio de la Oferta Enoturística de las Rutas del Vino de España (2009, p.19-29); Estudio de la Oferta Enoturística de las Rutas del Vino de España (2ํsemestre 2009, p.4-44).

(2) Recogida de cuestionarios: se ha realizado mediante correo electrónico, y sobre todo vía teléfono y fax en la mayor parte de los cuestionarios.

(3) Análisis de datos: que nos permite cumplir con los objetivos propuestos; análisis del perfil de bodegas, alojamientos y restaurantes, actividades enoturísticas de cada uno de los establecimientos, perfil de los visitantes, nivel de satisfacción y valoración de las actividades enoturísticas, análisis DAFO.

Tabla 3: Estructura cuestionario

\begin{tabular}{|c|c|c|c|}
\hline & Bodegas & Restaurantes & Alojamientos \\
\hline $\begin{array}{l}\text { Perfil de la } \\
\text { empresa }\end{array}$ & $\begin{array}{l}\text { - Datos generales de la empresa } \\
\text { - Tipo de propiedad, forma jurídica } \\
\text { - № de empleados y nivel formativo } \\
\text { - Acciones formativas } \\
\text { - Tamaño de la empresa, superficie de } \\
\text { cultivo } \\
\text { - Variedades de uva y producción anual } \\
\text { - Canales de distribución y } \\
\text { comercialización }\end{array}$ & $\begin{array}{l}\text { - Datos generales de la empresa } \\
\text { - Tipo de propiedad, forma jurídica } \\
\text { - № de empleados y nivel formativo } \\
\text { - Acciones formativas } \\
\text { - Capacidad local } \\
\text { - Ocupación media anual } \\
\text { - Precio medio menú por persona }\end{array}$ & $\begin{array}{l}\text { - Datos generales de la empresa } \\
\text { - Tipo de propiedad, forma jurídica } \\
\text { - № de empleados y nivel formativo } \\
\text { - Acciones formativas } \\
\text { - Número de habitaciones } \\
\text { - Ocupación media anual } \\
\text { - Precio medio habitación doble por } \\
\quad \text { persona } \\
\text { - Servicios que ofrece }\end{array}$ \\
\hline $\begin{array}{l}\text { Actividad } \\
\text { enoturística }\end{array}$ & $\begin{array}{l}\text { - Confirmación adhesión a la ruta } \\
\text { - Quien se encarga de la actividad } \\
\text { enoturística, formación } \\
\text { - Realización de inversiones }\end{array}$ & $\begin{array}{l}\text { - Confirmación adhesión a la ruta } \\
\text { - Realización de inversiones } \\
\text { - Incremento de rentabilidad } \\
\text { obtención de beneficios tras }\end{array}$ & $\begin{array}{l}\text { - Confirmación adhesión a la ruta } \\
\text { - Realización de inversiones } \\
\text { - Incremento de rentabilidad u } \\
\text { obtención de beneficios tras la }\end{array}$ \\
\hline
\end{tabular}

REDMARKA UIMA-Universidad de A Coruña - CIECID

Año VI, Número 11, (2013), v2 pp. 185-212

http://www.redmarka.org/

ISSN 1852-2300 


\begin{tabular}{|c|c|c|c|}
\hline & 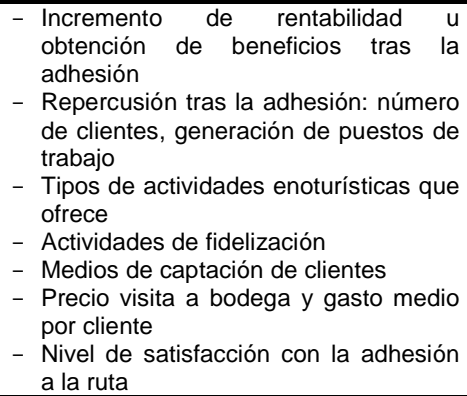 & $\begin{array}{l}\text { adhesión } \\
\text { - Repercusión tras la adhesión: } \\
\text { número de clientes, generación de } \\
\text { puestos de trabajo } \\
\text { - Tipos de actividades enoturísticas } \\
\text { que ofrece } \\
\text { - Actividades de fidelización } \\
\text { - Medios de captación de clientes } \\
\text { - Nivel de satisfacción con la } \\
\text { adhesión a la ruta }\end{array}$ & $\begin{array}{l}\text { adhesión } \\
\text { - } \text { Repercusión tras la adhesión: } \\
\text { número de clientes, generación de } \\
\text { puestos de trabajo } \\
\text { - Tipos de actividades enoturísticas } \\
\text { que ofrece } \\
\text { - Actividades de fidelización } \\
\text { - Medios de captación de clientes } \\
\text { - Nivel de satisfacción con la } \\
\text { adhesión a la ruta }\end{array}$ \\
\hline $\begin{array}{l}\text { Perfil } \\
\text { visitante }\end{array}$ & $\begin{array}{l}\text { - Procedencia de los visitantes } \\
\text { - Proporción nacional e internacional } \\
\text { - Período de mayor afluencia } \\
\text { - Grado de aceptación de las } \\
\text { actividades por los visitantes } \\
\text { - Imagen de la ruta }\end{array}$ & $\begin{array}{l}\text { - Procedencia de los visitantes } \\
\text { - Proporción nacional e internacional } \\
\text { - Período de mayor afluencia } \\
\text { - Gasto medio del visitante } \\
\text { - Imagen de la ruta }\end{array}$ & $\begin{array}{l}\text { - Procedencia de los visitantes } \\
\text { - Proporción nacional e internacional } \\
\text { - Período de mayor afluencia } \\
\text { - Estancia media de los visitantes } \\
\text { por noche } \\
\text { - Imagen de la ruta }\end{array}$ \\
\hline $\begin{array}{l}\text { Análisis } \\
\text { DAFO }\end{array}$ & \multicolumn{3}{|c|}{$\begin{array}{l}\text { Este apartado estudia las Debilidades, Amenazas, Fortalezas y Oportunidades desde el punto de vista de los oferentes de la } \\
\text { actividad enoturística. }\end{array}$} \\
\hline
\end{tabular}

Fuente: Elaboración propia

El proceso de envío y recepción de cuestionarios ha sido largo y complicado, comenzando el 1 de Abril y terminando de recibir las respuestas el 1 de Junio. Tras el envío por e-mail, fax y la puesta en contacto telefónico, hemos obtenido un nivel de respuesta de un $93,30 \%$ en bodegas, un $75,00 \%$ en restaurantes y un $81,25 \%$ en alojamientos.

Tabla 4: Ficha técnica del estudio

\begin{tabular}{|c|c|c|c|c|}
\hline Muestra & Bodegas & Restaurantes & Alojamientos & Total \\
\hline Universo de población & \multirow{2}{*}{\multicolumn{4}{|c|}{$\begin{array}{l}\begin{array}{l}\text { Bodegas, restaurantes y alojamientos adheridos a la Ruta del Vino del Bierzo } \\
\text { http://www.enoturismoenelbierzo.com/. }\end{array} \text { El Bierzo (Castilla y León). }\end{array}$}} \\
\hline Ámbito Geográfico & & & & \\
\hline $\begin{array}{l}\text { Tamaño poblacional } \\
\text { inicio del estudio }\end{array}$ & \multicolumn{3}{|c|}{ 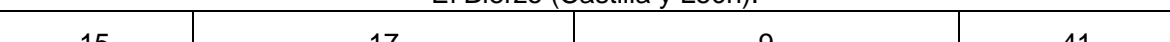 } & 41 \\
\hline $\begin{array}{l}\text { Tamaño poblacional } \\
\text { del estudio }^{10}\end{array}$ & 15 & 16 & 8 & 39 \\
\hline Tamaño Muestral & 14 & 13 & 6 & 33 \\
\hline Índice de Respuesta \% & $93,30 \%$ & $81,25 \%$ & $75,00 \%$ & $84,61 \%$ \\
\hline Error Muestral $(\alpha=0,05)$ & $+6,90 \%$ & $+12,01 \%$ & ${ }^{+}-20,41 \%$ & ${ }^{+}-6,83 \%$ \\
\hline Nivel de confianza & \multicolumn{4}{|c|}{$95 \% Z=1,96 p=q=0,5$} \\
\hline Método de recogida & \multicolumn{4}{|c|}{ Email, teléfono y fax } \\
\hline Fecha recogida & \multicolumn{4}{|c|}{1 Abril de 2013 a 1 de Junio de 2013.} \\
\hline
\end{tabular}

\section{Fuente: Elaboración propia}

En términos totales, este estudio obtuvo un índice de respuesta del 84,61\%, siendo el error muestral del +- 6,83 \% a un nivel de confianza del 95,00 \%.

\footnotetext{
${ }^{9}$ Este es el tamaño poblacional que existía cuando comenzamos nuestro estudio. La base de datos fue elaborado en base a los datos de la Ruta del Vino Bierzo "Enoturismo en el Bierzo" http://www.enoturismoenelbierzo.com/.

${ }^{10}$ Tamaño poblacional real del estudio, en base a las bajas y altas que pudimos contrastar a través de los contactos telefónicos con los encuestados.
}

REDMARKA UIMA-Universidad de A Coruña - CIECID

Año VI, Número 11, (2013), v2 pp. 185-212

http://www.redmarka.org/

ISSN 1852-2300 
TURISMO ENOLÓGICO Y RUTA DEL VINO... del Río, R; Álvarez, G; Vila, A; Iglesias, G.

\section{4.- ANÁLISIS DATOS}

Los resultados que se presentan a continuación corresponden al proceso de encuestación realizado a los establecimientos adheridos (bodegas, alojamientos y restaurantes) a la Ruta del Vino del Bierzo (Enoturismo en el Bierzo).

\section{1.- Perfil de de los establecimientos adheridos a la Ruta Enoturismo Bierzo (bodegas, restaurantes y alojamientos)}

En este apartado vamos a definir el perfil de los establecimientos apoyandonos en sus características mas relevantes; propiedad, forma jurídica, tamaño (número de empleados) y nivel formativo. Se observa (tabla 5) que la empresa familiar11 destaca en todos los subsectores analizados; la forma jurídica predominante en los tres sectores es la de Sociedad Limitada.

Tabla 5: Perfil de de los establecimientos adheridos a la Ruta "Enoturismo Bierzo"

\begin{tabular}{|c|c|c|c|c|}
\hline Perfil & Concepto & Bodegas & Restaurantes & Alojamientos \\
\hline Propiedad & $\begin{array}{l}\text { Familiar } \\
\text { No familiar }\end{array}$ & $\begin{array}{l}64,29 \% \\
35,71 \%\end{array}$ & $\begin{array}{l}\mathbf{8 3 , 3 3 \%} \\
16,67 \%\end{array}$ & $\begin{array}{l}69,23 \% \\
30,77 \%\end{array}$ \\
\hline Tipo sociedad & $\begin{array}{l}\text { Emp. Individual } \\
\text { S.L } \\
\text { S.A. } \\
\text { Soc. Coop. }\end{array}$ & $\begin{array}{c}7,14 \% \\
\mathbf{5 0 , 0 0 \%} \\
35,71 \% \\
7,14 \% \\
\end{array}$ & $\begin{array}{l}33,33 \% \\
66,67 \%\end{array}$ & $\begin{array}{l}38,46 \% \\
61,54 \%\end{array}$ \\
\hline Frecuencia de formación & $\begin{array}{l}\text { Continuamente } \\
\text { Ocasionalmente } \\
\text { Nunca }\end{array}$ & $\begin{array}{l}14,28 \% \\
85,72 \%\end{array}$ & $\begin{array}{l}16,67 \% \\
50,00 \% \\
33,33 \%\end{array}$ & $\begin{array}{l}71,43 \% \\
21,43 \%\end{array}$ \\
\hline Nivel formativo empleados & $\begin{array}{l}\text { Doctorado } \\
\text { Diplomados y licenciados } \\
\text { FP } \\
\text { Secundarios } \\
\text { Primarios } \\
\text { Sin estudios }\end{array}$ & $\begin{array}{l}71,43 \% \\
28,57 \%\end{array}$ & $100,00 \%$ & $\begin{array}{c}7,14 \% \\
30,77 \% \\
38,46 \% \\
36,36 \% \\
7,14 \%\end{array}$ \\
\hline Número de empleados & $\begin{array}{l}0<x<9 \\
10<x<50\end{array}$ & $\begin{array}{l}78,57 \% \\
21,43 \%\end{array}$ & $\begin{array}{l}\mathbf{8 3 , 3 3 \%} \\
16,67 \% \\
\end{array}$ & $\begin{array}{c}\mathbf{9 2 , 3 1 \%} \\
7,69 \% \\
\end{array}$ \\
\hline
\end{tabular}

Fuente: Elaboración Propia

Con respecto a la frecuencia de formación realizada por los trabajadores, mayoritariamente se realiza esta en los establecimientos de forma ocasional. El

\footnotetext{
11 Empresa Familiar: "Se pueden considerar empresas familiares todas las sociedades y empresas individuales que desarrollen sus actividades económicas, industriales y de producción de bienes y servicios, o administren y gestionen participaciones directas o indirectas de sociedades que desarrollan tales actividades y que están participadas de manera significativa por un grupo familiar que actúa con vocación de continuidad bajo una unidad de decisión y dirección en las que al menos un miembro del grupo familiar interviene de manera efectiva en la gestión de la empresa ostentando la capacidad de decisión sobre los aspectos más relevantes que le conciernen a la sociedad familiar". Ruiz (2000) en Gallego (2012, p. 6-7) en http://www.uco.es/estudia/catedras/catedra_prasa/img/0_x11_1339578030.pdf.
}

REDMARKA UIMA-Universidad de A Coruña - CIECID

Año VI, Número 11, (2013), v2 pp. 185-212

http://www.redmarka.org/

ISSN 1852-2300 
TURISMO ENOLÓgico y RUTA DEL VINO... del Río, R; Álvarez, G; Vila, A; Iglesias, G.

nivel formativo mayoritario varía en cada sector, universitario en bodegas, FP en restaurantes y estudios secundarios en los alojamientos. Tambien analizamos, la dimensión de los establecimientos teniendo en cuenta el número de trabajadores siendo la mayor parte microempresas.

Las bodegas destacan por tener una superficie de instalación entre los $1.001 \mathrm{y}$ $5.000 \mathrm{~m} 2(57,14 \%)$, las hectáreas de viñedo pertenecientes a cada bodega suelen ser menos de 50 hectáreas $(71,43 \%)$, y la producción anual en miles de litros es inferior a 100.000 I. (76,92\%). En términos de media las instalaciones son de 570,77 m2, 14,96 hectáreas de 200.000 litros. Los resultados indican que el 78,57\% cuentan con enólogo en plantilla en lugar de subcontratado. En cuanto a las variedades de uva más cultivadas son Godello y Doña Blanca (uva blanca), Mencía y Garnacha tintorera (uva tinta), siendo por excelencia la uva blanca. De las bodegas ninguna vende exclusivamente a nivel nacional, ya que un 64,29\% dedica algo menos de un $20 \%$ a la venta internacional, y un 28,57\% vende más de un $20 \%$ fuera de nuestras fronteras, además de destacar el 7,14\% restante cuya comercialización supera el $40 \%$ a nivel internacional. Los canales de distribución más utilizados son los distribuidores y la tienda en bodega $(96,43 \%)$, seguido de las vinotecas y la hostelería $(71,42 \%)$, los menos utilizados son los clubes de vinos $(42,85 \%)$ y las empresas de catering $(28,57 \%)$.

En los restaurantes cabe destacar que el aforo es superior a 200 personas (33,33\%), sin embargo la ocupación media anual es inferior al 50\% en la mayoría de los establecimientos (83,33\%). De manera individualizada hemos analizado el precio del menú, donde vemos que el $50 \%$ de los restaurantes tienen un precio de entre los 10 y $30 €$. En los alojamientos ocurre lo mismo que en el sector analizado anteriormente, la ocupación media anual no supera el $50 \%$ en la mayoría de alojamientos $(46,15 \%)$. El precio medio de la habitación doble supera los $50 €$ noche en el $46,15 \%$ de los mismos. Con respecto a la categoría, podemos destacar que el 53,85\% son alojamientos rurales, el resto son posadas $(30,77 \%)$ y hoteles $(15,38 \%)$.

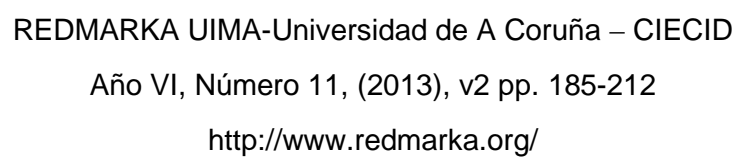


TURISMO ENOLÓgICO Y RUTA dEL VINO... del Río, R; Álvarez, G; Vila, A; Iglesias, G.

\section{2.- Oferta de actividades enoturísticas de las bodegas, restaurantes y alojamientos}

A continuación, analizamos las actividades relacionadas con el enoturismo puestas en práctica por los establecimientos; que servicios ofrecen, como captan clientes y consiguen su fidelización, además de comprobar que sistemas de publicidad utilizan, y el gasto medio de los clientes en cada visita.

Tabla 6: Oferta enoturística

\begin{tabular}{|c|c|c|c|c|}
\hline Actividades & Concepto & Bodegas & Restaurantes & Alojamientos \\
\hline Realizaron alguna inversión & $\begin{array}{l}\mathrm{Si} \\
\text { No }\end{array}$ & $100,00 \%$ & $\begin{array}{l}66,67 \% \\
33,33 \%\end{array}$ & $\begin{array}{l}15,39 \% \\
\mathbf{8 4 , 6 1 \%} \\
\end{array}$ \\
\hline $\begin{array}{l}\text { La adhesión ha generado } \\
\text { incremento de la rentabilidad }\end{array}$ & $\begin{array}{l}\mathrm{Si} \\
\text { No }\end{array}$ & $\begin{array}{l}35,71 \% \\
64,29 \%\end{array}$ & $\begin{array}{l}50,00 \% \\
50,00 \%\end{array}$ & $\begin{array}{l}35,71 \% \\
64,29 \%\end{array}$ \\
\hline $\begin{array}{l}\text { Ha notado algún beneficio tras la } \\
\text { adhesión }\end{array}$ & $\begin{array}{l}\mathrm{Si} \\
\text { No }\end{array}$ & $\begin{array}{l}71,43 \% \\
28,57 \% \\
\end{array}$ & $\begin{array}{l}50,00 \% \\
50,00 \%\end{array}$ & $\begin{array}{l}28,57 \% \\
71,43 \% \\
\end{array}$ \\
\hline $\begin{array}{l}\text { Incremento de los clientes tras la } \\
\text { adhesión }\end{array}$ & Sí, recibo más clientes & $100,00 \%$ & $100,00 \%$ & $100,00 \%$ \\
\hline $\begin{array}{l}\text { Ha generado empleo en su } \\
\text { empresa la adhesión }\end{array}$ & $\begin{array}{l}\text { No } \\
\text { Sí }\end{array}$ & $\begin{array}{c}92,86 \% \\
7,14 \% \\
\end{array}$ & $100,00 \%$ & $100,00 \%$ \\
\hline $\begin{array}{l}\text { Servicios de enoturismo } \\
\text { ofrecidos }\end{array}$ & $\begin{array}{l}\text { Venta de vino } \\
\text { Visita bodega } \\
\text { Degustación de vino } \\
\text { Catas } \\
\text { Cursos de cata } \\
\text { Visita viñedos } \\
\text { Actividades en los viñedos } \\
\text { Vendimia } \\
\text { Actividades elaboración de } \\
\text { vinos } \\
\text { Restaurante propio } \\
\text { Jornadas gastronómicas } \\
\text { Sala para eventos } \\
\text { Organización eventos mundo } \\
\text { del vino } \\
\text { Servicios de vinoterapia } \\
\text { Visitas guiadas por la zona } \\
\text { Seminarios en torno al vino } \\
\text { Degustación productos típicos } \\
\text { de la zona } \\
\text { Menús maridados } \\
\text { Presentación de vinos } \\
\text { Parte de un pack enoturístico }\end{array}$ & $\begin{array}{c}100,00 \% \\
100,00 \% \\
100,00 \% \\
100,00 \% \\
42,86 \% \\
71,43 \% \\
14,28 \% \\
7,14 \% \\
7,14 \% \\
28,57 \% \\
28,57 \% \\
\\
21,43 \% \\
7,14 \%\end{array}$ & $\begin{array}{l}50,00 \% \\
33,33 \% \\
\\
\\
83,33 \% \\
83,33 \% \\
33,33 \% \\
50,00 \%\end{array}$ & $\begin{array}{c}38,46 \% \\
30,77 \% \\
23,08 \% \\
15,38 \% \\
53,85 \% \\
7,69 \%\end{array}$ \\
\hline Captación clientes & $\begin{array}{l}\text { Páginas web } \\
\text { Oficinas de turismo } \\
\text { Agencias de viajes } \\
\text { Folletos } \\
\text { Prensa y/o radio }\end{array}$ & $\begin{array}{c}78,57 \% \\
28,57 \% \\
21,43 \% \\
100,00 \% \\
42,86 \%\end{array}$ & $\begin{array}{c}83,33 \% \\
33,33 \% \\
16,67 \% \\
100,00 \% \\
50,00 \%\end{array}$ & $\begin{array}{l}92,31 \% \\
61,54 \% \\
38,46 \% \\
92,31 \% \\
30,77 \%\end{array}$ \\
\hline Fidelización de clientes & $\begin{array}{l}\text { Cursos de cata } \\
\text { Club de amigos } \\
\text { Cursos de enología } \\
\text { Tertulias } \\
\text { Cursos de viticultura } \\
\text { Jornadas gastronómicas }\end{array}$ & $\begin{array}{l}14,29 \% \\
28,57 \%\end{array}$ & $33,33 \%$ & $23,08 \%$ \\
\hline
\end{tabular}

REDMARKA UIMA-Universidad de A Coruña - CIECID

Año VI, Número 11, (2013), v2 pp. 185-212

http://www.redmarka.org/

ISSN 1852-2300 
TURISMO ENOLÓgICO Y RUTA DEL VINO... del Río, R; Álvarez, G; Vila, A; Iglesias, G.

\begin{tabular}{|l|l|l|c|c|}
\hline \multirow{2}{*}{$\begin{array}{l}\text { Jornadas micológicas } \\
\text { Cursos online }\end{array}$} & $\mathbf{1 6 , 6 6 \%}$ & $\mathbf{1 5 , 3 8 \%}$ \\
\hline No realizan ninguna actividad & $\mathbf{8 5 , 7 1 \%}$ & $\mathbf{6 6 , 6 6 \%}$ & $\mathbf{6 9 , 2 3} \%$ \\
\hline
\end{tabular}

Fuente: Elaboración propia

Es de destacar que en la totalidad de los establecimientos se realizan actividades relacionadas con el enoturismo, dirigidas en el $42,86 \%$ de las bodegas por el gerente de la bodega o por el propio responsable de enoturismo $(35,71 \%)$, de los que el $42,86 \%$ de los mismos cuenta con estudios especializados en turismo o similares, esencialmente, cursos o ingenierías agrícolas. También quisimos saber el coste que supone una visita a las instalaciones, en donde el $57,14 \%$ no supera los $6 €$ acompañada en el $92,85 \%$ de los encuestados de la degustación de uno los vinos de la empresa. Finalmente en cuanto al gasto medio que realizan los visitantes oscila entre los 11 y $25 €(42,90 \%$ de los encuestados).

Para el caso de los restaurantes $(66,67 \%)$, han realizado algún tipo de inversión de las que destacan con un 66,67\% los cursos de formación para empleados (servicio de vinos) y con $50,00 \%$ la tematización de los estabecimientos en torno al mundo del vino. La oferta se caracteriza por estar relacionada con las catas y los servicios propios de la restauración. En relación al precio del menú, el 50,00\% de los restaurantes ronda entre los 10 y los $30 €$, y tan sólo un $16,67 \%$ tiene un menú más económico, inferior a los $10 €$.

Se confirma que la mayora de los alojamientos $(53,85 \%)$ ofrece servicios simplemente de alojamiento, y tan sólo el 23,08\% ofrece además servicios de restauración así como los vinculados al mundo del vino. EL $84,61 \%$ de los alojamientos de la Ruta ha realizado inversiones destacando la tematizacion en torno al mundo del vino (76,92\%). Sin embargo se da un dato negativo y es que el $64,29 \%$ de los alojamientos afirma que la adhesión no les ha supuesto ningún beneficio, lo que podría llevarles a a abandonar la adhesión. Comenta los servicios ofertados destacan el alojamiento integrado en paquetes enoturísticos, la venta de vinos, la visita a los viñedos, así como el restaurante. En relación al precio medio por

REDMARKA UIMA-Universidad de A Coruña - CIECID

Año VI, Número 11, (2013), v2 pp. 185-212

http://www.redmarka.org/

ISSN 1852-2300 
TURISMO ENOLÓgico y RUTA DEL VINO... del Río, R; Álvarez, G; Vila, A; Iglesias, G.

habitación doble (por noche), el 66,15\% de los encuestados tiene un precio de entr los 20 y $50 € /$ noche y tan sólo el $15,38 \%$ tiene un precio inferior a $20 € /$ noche.

En cuanto a los servicios ofertados destacan esencialmente la venta de vino, la visita a las bodegas, la degustación de vinos y catas así como los propios servicios de restauración y alojamiento integrados. Por otro lado, los medios de captación más usados son los folletos y la publicidad en páginas web. Sin embargo, al hablar de actividades de fidelización, debemos destacar el elevado porcentaje de empresas que no realizan ninguna de las actividades mencionadas y en el caso de realizarlas las más destacadas son las jornadas gastronómicas.

\section{3.- Perfil de los enoturistas desde el punto de vista de los establecimientos objeto de estudio}

Analizar el perfil de los enoturistas que visitan la Ruta es otro de los objetivos que nos hemos planteado a la hora de realizar este trabajo de investigación. Los datos obtenidos nos dejan ver que la procedencia principal de los enoturistas es nacional (34\%) destacando así mismo. Ahora bien si analizamos por Comunidades Autónomas comprobamos que en los tres subsectores los visitantes nacionales provienen principalmente de Castilla y León, Galicia y Madrid y los visitantes internacionales por su parte provienen principalmente de EE.UU, Inglaterra y Francia.

Otro punto a analizar fue el conocer los periodos del año de mayor afluencia de visitantes, comprobando que durante el verano es el periodo en el cual las bodegas reciben más turistas, al igual que en los puentes y festivos.

Tabla 7: Perfil del visitante

\begin{tabular}{|l|c|c|c|}
\hline \multicolumn{1}{|c|}{ Perfil } & Bodegas & Restaurantes & Nacional \\
\hline $\begin{array}{l}\text { Procedencia principal del visitante } \\
\text { Procedencia principal visitante por }\end{array}$ & Nacional & Nacional \\
\hline $\begin{array}{l}\text { Procedencia principal del visitante } \\
\text { extranjero }\end{array}$ & Ealicia & EE.UU. & Galicia \\
\hline $\begin{array}{l}\text { Principal época de afluencia } \\
\text { Gasto medio del cliente }\end{array}$ & $\begin{array}{c}\text { Verano y Puentes y } \\
\text { festivos }\end{array}$ & $\begin{array}{c}\text { Verano y Puentes y festivos } \\
\text { EE.UU. }\end{array}$ & $\begin{array}{c}\text { Puentes y festivos y } \\
\text { Semana Santa }\end{array}$ \\
\hline
\end{tabular}

REDMARKA UIMA-Universidad de A Coruña - CIECID

Año VI, Número 11, (2013), v2 pp. 185-212

http://www.redmarka.org/

ISSN 1852-2300 
TURISMO ENOLÓgICO Y RUTA DEL VINO... del Río, R; Álvarez, G; Vila, A; Iglesias, G.

Fuente: Elaboración propia

\section{4.- Nivel de satisfacción de los establecimientos tras su adhesión a la Ruta}

Con el objetivo de analizar el nivel de satisfacción que tienen los establecimientos con relación a su pertenencia a la Ruta del Bierzo hemos solicitado a los mismos su valoración utilizando una escala Likert de 1 a 5 , desde muy poco satisfecho, a muy satisfecho. Lo más destacable de este punto, es el alto porcentaje de satisfacción media por parte de los establecimientos que pertenecen a la Ruta del Vino Enoturismo en el Bierzo. Analizando por subsectores, los restaurante son los más satisfechos, seguido por las bodegas, y los alojamientos mientras que se muestran insatisfechos un $15,38 \%$ de los alojamientos.

Tabla 8: Nivel de satisfacción

\begin{tabular}{|c|c|c|c|c|c|}
\hline & Concepto & Bodegas & Restaurantes & Alojamientos & Cómputo global \\
\hline \multirow{3}{*}{ Nivel de satisfacción } & Satisfecho & $42,86 \%$ & $\mathbf{5 0 , 0 0} \%$ & $38,46 \%$ & $43,77 \%$ \\
\cline { 2 - 6 } & Neutro & $\mathbf{5 7 , 1 4} \%$ & $\mathbf{5 0 , 0 0} \%$ & $\mathbf{4 6 , 1 5 \%}$ & $51,10 \%$ \\
\cline { 2 - 6 } & No Satisfecho & $0 \%$ & $0 \%$ & $15,38 \%$ & $5,13 \%$ \\
\hline
\end{tabular}

Fuente: Elaboración propia

\section{5.- Imagen percibida del destino por los establecimientos}

Para analizar la imagen percibida del destino por los establecimientos solicitamos que valorasen una serie de afirmaciones (se trata de una zona tranquila, hay abundante oferta enoturística, así como de infraestructuras, entre muchas otras) utilizando una escala Likert, donde se valoraba de 1 a 5 , de muy mala a muy buena.

La calidad de la zona-tranquilidad con una puntuación de 4,59 es la más valorada seguida de su paisaje $(4,09)$, la oferta gastronómica $(4,25)$ y la oferta cultural con un 4,13 de puntuación. Lo menos valorado es la oferta enoturística con 3,66, oferta de ocio y recreo $(3,67)$ y la oferta de infraestructuras con una puntuación de 3,71 , lo que indica que deben mejorar.

\section{6.- Valoración de la actividad enoturística de la Ruta}

La opinión que tienen los tres sectores sobre la actividad enoturística en la Ruta del Vino Enoturismo en el Bierzo es bastante alentadora, ya que como podemos 
TURISMO ENOLÓgico y RUTA DEL VINO... del Río, R; Álvarez, G; Vila, A; Iglesias, G.

observar la totalidad de los sectores se ha decantado por una opinión neutra o buena, salvo los restaurantes que un 15,38\% consideran que debería mejorar.

Tabla 9: Valoración enoturística de la zona

\begin{tabular}{|c|c|c|c|}
\hline Valoración & Bodegas & Restaurantes & Alojamientos \\
\hline Muy Buena & $14,29 \%$ & $0 \%$ & $0 \%$ \\
\hline Buena & $21,42 \%$ & $15,39 \%$ & $16,67 \%$ \\
\hline Neutro & $\mathbf{6 4 , 2 9} \%$ & $\mathbf{6 9 , 2 3} \%$ & $\mathbf{8 3 , 3 3} \%$ \\
\hline Debe mejorar & $0 \%$ & $15,38 \%$ & $0 \%$ \\
\hline
\end{tabular}

Fuente: Elaboración propia

\section{7.- DAFO a partir de la información proporcionada por los establecimientos encuestados}

En este apartado presentamos el resultado final del DAFO analizado, herramienta que nos permitirá conocer las Debilidades y Fortalezas que se derivan de la propia Ruta, así como las Amenazas y Oportunidades que son agentes externos a la misma. Los dos primeros dependen de las propias características de la Ruta, mientras que los dos segundos están más relacionados con el entorno que rodea a la Ruta del Vino. Se elaboraron tres DAFOs con las aportaciones de cada uno de los miembros de la ruta: bodegas, restaurantes, alojamientos, y el cuarto que recogemos en la tabla 10 es de elaboración propia a partir de los anteriores. Debemos remarcar que todo lo recogido en los DAFOs son apreciaciones de los miembros de la Ruta del Vino.

Tabla 10: DAFO Resumen del DAFO bodegas, DAFO restaurantes y DAFO alojamientos DEBILIDADES FORTALEZAS

REDMARKA UIMA-Universidad de A Coruña - CIECID

Año VI, Número 11, (2013), v2 pp. 185-212

http://www.redmarka.org/

ISSN 1852-2300 


1. Escasa oferta enoturística.
2. Escasa oferta cultural.
3. Situación geográfica.
4. Desconocimiento de la Ruta.
5. Escasa publicidad.
6. Bodegas pequeñas de carácter familiar, sin dedicación exclusiva
al enoturismo.
7. Consejo Regulador sin capacidad de prescripción.
8. Personal poco cualificado.
9. Escaso dominio de idiomas.
10. Carencia de bodegas con buenas infraestructuras para realizar
visitas.

11. Falta de innovación.

12. Se formó tarde y muy lentamente.

13. Su certificación coincidió con el inicio de la crisis.

14. Zona poco conocida.

15. Instalaciones de las Bodegas no destinadas a usos turísticos.

16. Limitación en los canales de promoción.

17. Muy poco marketing en redes sociales.

18. Falta de apoyo de las administraciones.

19. Certificación muy reciente de la Ruta, es una ruta joven.

20. Falta de cohesión de sus integrantes, para seguir en un camino con unos objetivos comunes.

21. No disponer de una señalización de la ruta.

22. Falta de promoción al exterior y de iniciativas.

23. Situación de crisis en la que estamos inmersos actualmente.

24. Falta de apoyo por parte de las administraciones.

25. Existencia de rutas en España que ya cuentan con una solidez de muchos años.

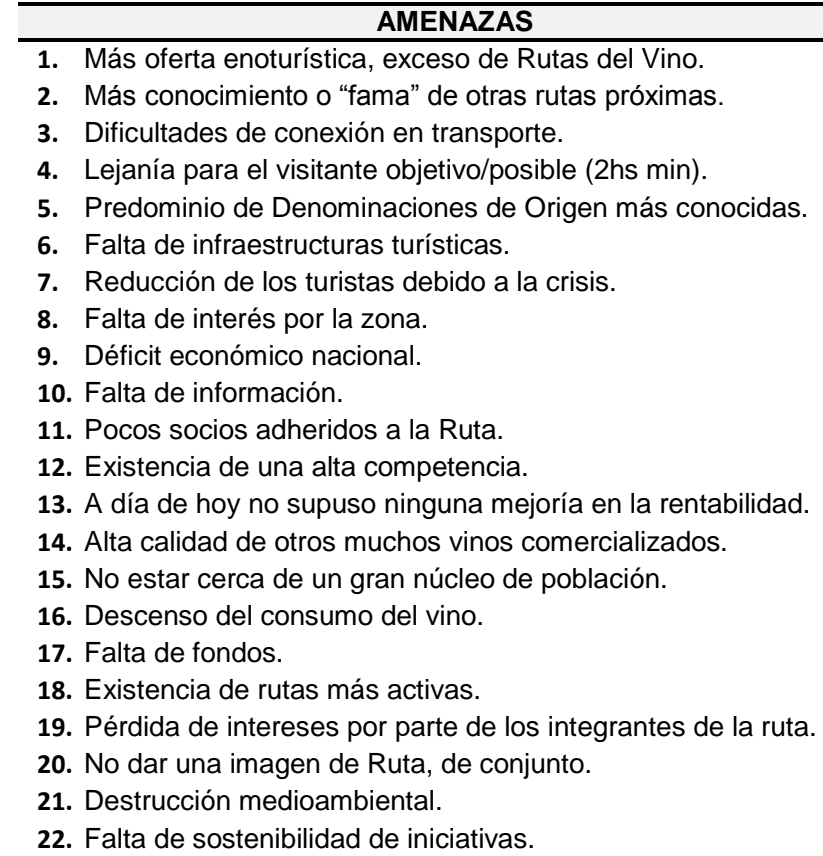

1. Oferta de naturaleza y paisajes singulares.

2. Alegre carácter y amabilidad de las gentes.

3. Localización.

4. Productos de calidad.

5. Gran oferta turística, destacable en turismo rural.

6. Buenas sinergias entre bodegas $y$ establecimientos.

7. Vinos del Bierzo cada día más reconocidos como singulares y de calidad.

8. Incremento del conocimiento de la D.O Bierzo.

9. Calidad cultural, paisajística arquitectónica y gastronómica.

10. Excelentes vinos.

11. Gran variedad.

1. Zona atractiva paisajísticamente.

2. Alta calidad y potencialidad de los vinos.

3. Apuesta decidida por el enoturismo.

4. Trabajo conjunto de empresas de la ruta.

5. Grandes lugares y monumentos Patrimonio de la Humanidad dentro de la Ruta como son por ejemplo las Médulas.

6. Lugar Reserva de la Biosfera.

7. Excelente gastronomía.

8. Zona privilegiada.

9. Estar en el camino de Santiago.

10. Novedad en la zona.

11. Desarrollo de un tipo de turismo nuevo en la zona.

1. La novedad del producto frente a otras rutas.

2. Cercanía de Galicia y su similitud en carácter de las personas.

3. Facilidad y disponibilidad de fechas para las reservas.

4. Consolidación en los destinos de interior.

5. Potencial de la zona por recursos naturales y patrimonio: historia, camino de Santiago.

6. Creación del Museo Nacional de Energía.

7. Promocionar los vinos.

8. Promocionar la comarca.

9. Captación de un mayor número de enoturistas.

10.Gran variedad de oferta.

11.Modalidad de turismo en expansión.

12.Captación de turismo de proximidad.

13.Desarrollo de las redes sociales.

14.Se trata de un gran proyecto.

15.Se le está poniendo muchas ganas y empeño porque algún día resurgiremos de esta crisis.

16.Oportunidad para los diversos establecimientos en dar a conocer el vino de la región.

Fuente: Elaboración propia.

REDMARKA UIMA-Universidad de A Coruña - CIECID

Año VI, Número 11, (2013), v2 pp. 185-212

http://www.redmarka.org/

ISSN 1852-2300 
TURISMO ENOLÓgico y RUTA DEL VINO... del Río, R; Álvarez, G; Vila, A; Iglesias, G.

Para concluir con el análisis DAFO citar algunos puntos relevantes en los que todos los establecimientos de la ruta están de acuerdo.

- Debilidades: destaca la certificación reciente de la Ruta, la falta de apoyo de las administraciones, la escasa oferta cultural y enoturística, así como la propia situación geográfica y la falta de innovación y publicidad, así como, la existencia de otras rutas de más trayectoria.

- Fortalezas: para los tres subsectores la oferta de naturaleza y paisajes singulares es uno de los puntos más destacados, así como los productos de calidad y la gran oferta gastronómica del Bierzo, la excelencia de sus vinos y la ferviente apuesta por el enoturismo en la zona, así como por asentarse en la Ruta Jacobea.

- Amenazas: en este apartado los establecimientos coinciden en que el exceso de rutas en España, así como la coyuntura económica por la que estamos pasando es una amenaza que afecta de forma directa a la afluencia de visitantes; que junto con la falta de infraestructuras y la escasez de socios adheridos a la ruta, están provocando una reducción de los turistas, así como del consumo de vino.

- Oportunidades: los puntos más destacados, son la consolidación de destinos de interior, el gran potencial de la zona tanto paisajístico, como cultural y gastronómico, el promocionar los vinos y con ellos la comarca de el Bierzo; y sobre todo la gran novedad del producto en la comarca y el potencial de desarrollo de las redes sociales, que suponen una lanzadera para los distintos establecimientos para dar a conocer los vinos de la zona.

\section{5.- CONCLUSIONES Y FUTURAS LÍNEAS DE INVESTIGACIÓN}

REDMARKA UIMA-Universidad de A Coruña - CIECID

Año VI, Número 11, (2013), v2 pp. 185-212

http://www.redmarka.org/

ISSN 1852-2300 
TURISMO ENOLÓgico y RUTA DEL VINO... del Río, R; Álvarez, G; Vila, A; Iglesias, G.

Durante el último siglo se están produciendo importantes cambios en el sector turístico debido a una mayor exigencia de los turistas que ya no sólo viajan a los destinos tradicionales (sol y playa) sino que en la actualidad demandan otros productos y destinos, relacionados con la cultura, la gastronomía, el deporte, etc.. Todo ello ha dado lugar al nacimiento de nuevos productos que satisfagan la nueva demanda de los consumidores actuales.

Uno de estos nuevos productos lo constituyen las Rutas del Vino que combina el turismo y el vino, dando lugar al denominado turismo enológico. Con este tipo de turismo España está consiguiendo generar un flujo importante de turistas hacia zonas rurales, lo que se convierte en un importante dinamizador económico de la zona.

Con la realización de este proyecto se pretende analizar la oferta de la ruta enoturística del Bierzo de reciente certificación, concretamente en el año 2011. La investigación empírica realizada y previamente expuesta nos permite extraer las siguientes conclusiones:

- Los establecimientos de la "Ruta del Vino Enoturismo en el Bierzo" (bodegas, restaurantes, alojamientos) son mayoritariamente empresas de propiedad familiar, y en lo que respecta a su tamaño el perfil más común es el de PYMES, más concretamente microempresas, bajo la forma jurídica de Sociedades Limitadas.

- En lo que respecta al nivel de formación de los empleados difiere dependiendo del tipo de establecimiento analizado. Las bodegas cuenta mayoritariamente con empleados que poseen una titulación superior (Licenciatura o Diplomatura); en el caso de los alojamientos la formación de sus empleados es más variada, forman parte de su plantilla tanto trabajadores con formación secundaria como con titulaciones superiores; y finalmente el 100,00 \% de los empleados de los restaurantes tienen una formación secundaria.

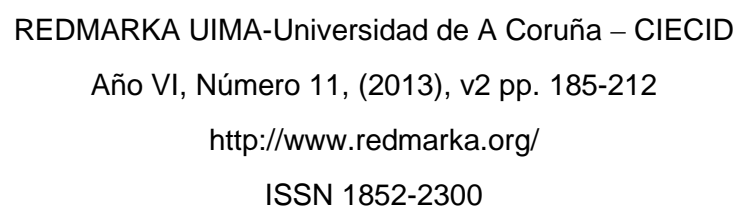


TURISMO ENOLÓgico y RUTA DEL VINO... del Río, R; Álvarez, G; Vila, A; Iglesias, G.

- La mayor parte de establecimientos de nuestra muestra lleva a cabo actividades formativas de forma ocasional y la adhesión a la Ruta no ha supuesto la generación de puestos de trabajo en ninguno de los tres tipos de establecimientos analizados.

- Las bodegas adheridas a la ruta en su mayoría cuentan entre su personal con un enólogo propio, y por lo tanto, no subcontratan el servicio a terceras empresas. La principal variedad de uva que utilizan para la producción del vino es en el caso de la uva blanca el Godello y de las tintas el Mencía y comercializan sus productos a través de distribuidores y tiendas en bodega. Todas las bodegas adheridas a la ruta comercializan parte de su producción a nivel internacional.

- Los restaurantes tienen un nivel medio de ocupación anual que ronda el 50,00 $\%$, con una capacidad de entre 100 y 300 personas y con un precio de menú de entre unos 10 y $30 €$ por persona. Y para las bodegas el precio medio de la visita que incluye la visita con la degustación de al menos un vino ronda entre los 3 y los $30 €$ por visitante haciendo un gasto medio por persona de entre unos $10 \mathrm{y}$ unos $50 €$.

- En cuanto a la actividad enoturística desarrollada en estos establecimientos, en el $100,00 \%$ de los casos han realizado algún tipo de inversión sobre todo en lo referente a la tematización del establecimiento en torno al mundo del vino, con el único problema que la adhesión no está dando frutos hasta el momento, puesto que el $65,42 \%$ de los encuestados afirman que no les ha generado ningún beneficio ni ha incrementado su rentabilidad.

- Haciendo una breve explicación de las actividades que disponen tanto las bodegas, alojamientos y restaurantes, las que más destacan, son la venta de vinos así como cursos de cata para que los visitantes a las bodegas puedan ampliar sus conocimientos sobre el vino, la degustación de productos típicos de 
TURISMO ENOLÓgico y RUTA DEL VINO... del Río, R; Álvarez, G; Vila, A; Iglesias, G.

la zona y de sus vinos, los menús maridados, así como el alojamientos integrado en paquetes enoturísticos.

- Cualquier establecimiento debe realizar actividades con el único propósito de fidelizar a los clientes. En el caso del $85,71 \%$ de los establecimientos de la zona del Bierzo encuestados, no lo hacen. No obstante, el 14,29 \% que si realiza actividades, destacan el Club de amigos, las jornadas gastronómicas, y los cursos de cata.

- Tratando de captar nuevos clientes los recursos más utilizados son mediante elaboración de folletos, así como mediante publicidad en páginas web, ya que vivimos en el mundo de las tecnologías y como comúnmente se dice es renovarse o morir.

- En relación con el perfil de los enoturistas, es necesario destacar que la principal procedencia de los turistas es nacional, mientras que si hablamos de procedencia internacional, los enoturistas vienen atraídos desde países como Inglaterra, Holanda, Francia y de lugares tan lejanos como los EEUU o México.

- El período en que estos establecimientos reciben un mayor número de visitas es durante la época estival y los puentes y festivos, mientras que en las épocas de vendimias es cuando menor es la afluencia.

- Analizando las bodegas comprobamos la actividad preferida por los turistas del vino, es la degustación de vinos en la bodega. Sin embargo, lo que más atrae a los enoturistas según la valoración de nuestros encuestados, es la tranquilidad y la naturaleza de la zona; ven el Bierzo como un lugar de descanso, donde se respira aire limpio y lejos de las grandes urbes a las que están acostumbrados, además de contar con una importante oferta enoturística, gastronómica y de hospedaje a lo largo de toda la comarca.

- Por último es necesario decir que estos tres subsectores adheridos a la Ruta de El Bierzo, se encuentran satisfechas con su adhesión, ya que han mantenido el número de clientes e incluso en algún caso han llegado a aumentarlo.

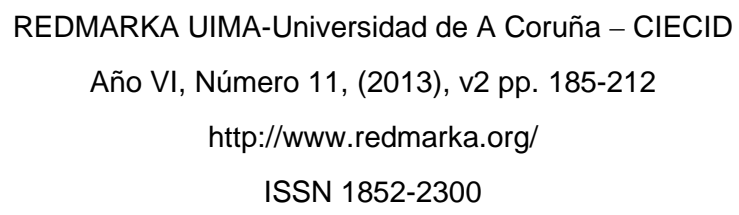


TURISMO ENOLÓgico y RUTA DEL VINO... del Río, R; Álvarez, G; Vila, A; Iglesias, G.

- La satisfacción con respecto a la Ruta del Bierzo es semejante en los tres subsectores (bodegas, alojamientos y restaurantes) y es positiva, pero sin acabar de ser convincente al cien por cien, puesto que el 75,53\% de los encuestados nos afirma que no está satisfecho pero tampoco está insatisfecho del todo.

- Ahora bien, si quisiéramos obtener un valor medio, es de 3,5 puntos (en una escala del 1 al 5), lo que nos lleva a concluir, que los establecimientos del Bierzo están medianamente satisfechos, con el único problema de que aún no acaba de hacerse firme la Ruta, contando con la escasa vigencia que lleva desarrollada hasta el momento.

- Una vez conocida la satisfacción de los establecimientos tras su adhesión a la Ruta comprobamos la satisfacción conforme a la situación de la actividad enoturística cuyo resultado fue semejante al anterior, puesto que más del $50,00 \%$ de los encuestados le otorga una valoración neutra, es decir de 3 puntos de media. Algo que nos lleva a pensar en el escaso recorrido que lleva hasta el momento la Ruta pero del cual se están haciendo grandes avances, ya que es una de las pocas que con su escaso tiempo de certificación se atreve a realizar jornadas y congresos de Enoturismo.

Una vez analizados el perfil de las empresas, las actividades de enoturismo realizadas y de determinar el perfil de los propios visitantes, les planteamos que nos trataran de confeccionar un análisis DAFO, en donde nos planteasen las principales debilidades, amenazas, fortalezas y oportunidades que percibieran a la hora de competir con otras Rutas del Vino. Elaborado este análisis comprobamos como el Bierzo y su Ruta de Enoturismo, están empezando a aflorar a paso lento pero firme. Están comenzando con fuerza en el mundo del Enoturismo y tratando de representar más la marca Bierzo. Entre los avances que se están llevando a cabo en 'Bierzo Enoturismo' continúan desarrollando la oferta turística vinculada al mundo del vino, cursos formativos y temas audiovisuales. 
TURISMO ENOLÓgico y RUTA DEL VINO... del Río, R; Álvarez, G; Vila, A; Iglesias, G.

Tienen tan presente el posicionar el enoturismo en el mercado, que incluso estudian organizar un congreso nacional y otro internacional de enoturismo en el Bierzo, para potencializar la imagen de la marca en el sector y ofrecer un centenar de productos turísticos diferenciados, entre los que podemos señalar rutas de senderismo asociadas al vino y la potenciación de la relación de la comarca vinícola con el Patrimonio de la Humanidad. Por otro lado, quieren promocionar más de cien productos turísticos para atraer a las visitas y así tratar de ser diferenciadores con respecto a otras Denominaciones de Origen. En este sentido, tratan de integrar gastronomía y enoturismo, las rutas de senderismo, el cicloturismo, la historia y su patrimonio histórico artístico, la visita a yacimientos arqueológicos desde una bodega. Incluso hace un par de meses han publicado nuevas propuestas como son los productos Catabierzo y Degustabierzo. Este es un punto muy fuerte frente a otras comunidades como es Galicia, donde no se está llevando a cabo ninguna iniciativa de este tipo, resultando ser una novedad en una ruta tan reciente como la del Bierzo y por la cual obtendrán una mayor repercusión social.

Como continuación de esta investigación me gustaría dejar abiertas posibles líneas de investigaciones futuras, que serían interesantes realizar:

- Realizar este estudio ampliándolo a toda la oferta de la ruta no sólo a estos tres subsectores (bodegas, restaurantes y alojamientos), esto nos proporcionaría información de una gran importancia y utilidad para tratar de incorporar nuevos miembros a la Ruta y así poder ampliar la oferta para atraer un mayor número de enoturistas.

- Realizar un estudio, similar al que hemos realizado, pero centrándonos en el punto de vista de la demanda, de esta manera los distintos establecimientos podrían conocer lo que de verdad atrae a los amantes del vino o enoturistas para poder ofertarlo, satisfaciendo de esta manera sus necesidades y deseos.

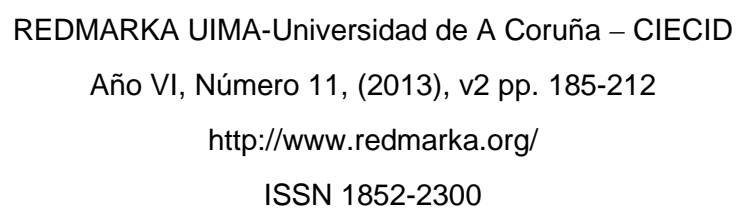


TURISMO ENOLÓgico y RUTA DEL VINO... del Río, R; Álvarez, G; Vila, A; Iglesias, G.

- Realizar una comparativa de análisis de Oferta con todas las Rutas del vino a nivel de la Comunidad Autónoma de Castilla y León.

- Realizar una comparativa de análisis de Oferta entre las Rutas del vino de la Comunidad de Galicia y de la de Castilla y León por su proximidad geográfica.

- Realizar una comparativa de análisis de Oferta entre las Rutas del vino a nivel nacional.

\section{BIBLIOGRAFÍA}

ACEVIN (2009a). Estudio de la Oferta Enoturística de las Rutas del Vino de España (2009). España: Asociación Española de Ciudades del Vino. Disponible en: http:// www.rutadelvinoriberadelduero.es/desc adj observatorio.php?id=4

ACEVIN (2009). Estudio de la Oferta Enoturística de las Rutas del Vino de España. España: Asociación Española de Ciudades del Vino. Disponible en http://www.wineroutesofspain.com/bd/archivos/archivo71.pdf.

ACEVIN (2010). Guía de la Sostenibilidad de empresas del sector enoturístico. España: Asociación Española de Ciudades del Vino.

ACEVIN (2012a). Guía de rutas del vino de España. España: Asociación Española de Ciudades del Vino. Disponible en: http://www.wineroutesofspain.com/bd/archivos/archivo121.pdf

ACEVIN (2012b). Informe de visitantes a bodegas asociadas a las Rutas del Vino de España. Año 2011. España: Asociación Española de Ciudades del Vino. Disponible

en:

http://www.wineroutesofspain.com/static/publicaciones/otros/An\%C3\%A1lisis \%20Visitantes\%20Bodegas\%20Rutas\%20del\%20Vino\%202011.pdf.

Alpízar Padilla, V. A. \& Maldonado Avalos, Mª M. (2011). Integración de la ruta del vino en Querétaro, un producto innovador. Revista Quivera. Revista De Estudios Urbanos, Regionales, Territoriales, Ambientales y Sociales, (2), 97109.

Disponible

en

http://www.uaemex.mx/fapur/docs/quivera/Quivera2_2009.pdf\#page=101

Álvarez García, J.; del Río Rama, M.C.; Fraiz Brea, J.A. \& Vazquez de Miranda, H. (2012). Análisis desde el punto de vista de la oferta. Bodegas ruta del vino Rías Baixas, XVII Congreso AECIT, Carballiño (Ourense). 
TURISMO ENOLÓgico y RUTA DEL VINO... del Río, R; Álvarez, G; Vila, A; Iglesias, G.

Andreu, R. y Verdú, L. (2012). Turismo enológico en Alicante: la ruta del vino en el municipio de Pinoso. Cuadernos de Turismo, Julio-Diciembre, 35-61.

Denominación de Origen Bierzo (DO Bierzo). Disponible en http://www.crdobierzo.es/ Fecha de consulta: (29/04/2013).

Denominaciones de Origen de Castilla y León (Turismo Castilla y León). Disponible en:

http://www.turismocastillayleon.com/cm/turcyl/tkContent?pgseed=1371157325

741\&idContent=91\&locale=es ES\&textOnly=false. Fecha de consulta: (17/05/2013).

DTS Consultores (2007). Identificación y puesta en valor de rutas turísticas para la región del Coquimbo. Chile: Gobierno de Chile. Disponible en: http://www.tecturcoquimbo.cl/pdfs/Informe-Rutas-Turisticas.pdf.

Enoturismo en el Bierzo. Disponible en: http://www.enoturismoenelbierzo.com/.Fecha de consulta (02/04/2013).

López-Guzmán, T. \& Sánchez Cañizares, S.M. (2008). La creación de productos turísticos utilizando rutas enológicas. Pasos. Revista de Turismo y Patrimonio Cultural, 6(2), 159-171. Disponible en: http://www.pasosonline.org/Publicados/6208special/PASOS14.pdf\#page=32.

Ministerio de Agricultura, alimentación y medio ambiente (MAGRAMA). Disponible en: http://www.magrama.gob.es/es/. Fecha de consulta: (07/04/2013).

Miranda Escolar, B., \& Fernández Morueco, R. (2011). Vino, turismo e innovación: las Rutas del Vino de España, una estrategia integrada de desarrollo rural. Estudios de Economía Aplicada, 29(1), 129-164. Disponible en web: http://www.revista-eea.net/documentos/29117.pdf

Ramis Hernández, A. (2010). Turismo y Vino en el Mundo. El caso de bodegas Enrique Mendoza. España: Apuntes de la Universidad de Alicante. Disponible en

web:

http://rua.ua.es/dspace/bitstream/10045/15168/1/Turismo\%20y\%20vino\%20e n\%20el\%20mundo_Ramis.pdf

Recevin (2006). Carta Europea del Enoturismo. Red Europea de Ciudades del Vino. Disponible en: http://www.recevin.net/downloads/Charte ES.pdf

Rodríguez García, J.; López-Guzmán, T.; Sánchez Cañizares, S. \& Jiménez García, M. (2010). Turismo del vino en el Marco de Jerez. Un análisis desde la perspectiva de la oferta. Cuadernos de Turismo, (26), 217-334

Rodríguez García, J.; Vieira Rodríguez, Á.; López-Guzmán, T. (2012). Segmentación Del Perfil De Enoturista. En La Ruta Del Vino Del Marco De Jerez-XérèsSherry. Turismo y Desarrollo Local, (13).

REDMARKA UIMA-Universidad de A Coruña - CIECID

Año VI, Número 11, (2013), v2 pp. 185-212

http://www.redmarka.org/

ISSN 1852-2300 
TURISMO ENOLÓgico y RUTA DEL VINO... del Río, R; Álvarez, G; Vila, A; Iglesias, G.

Rutas del Vino de España. Disponible en: http://www.wineroutesofspain.com/. Fecha de consulta: (03/04/2013).

Rutas del Vino de España: Ruta Ribera del Duero. Disponible en: http://www.wineroutesofspain.com/ver/2680/Ribera-del-Duero.html. Fecha de consulta: (20/04/2013).

Rutas del Vino del Duero. Disponible en: http://www.rutadelvinoriberadelduero.es/ Fecha de consulta: (12/05/2013).

Socios de la Ruta del Bierzo. Disponible en. http://www.enoturismoenelbierzo.com/buscarsocios.php. Fecha de consulta: (06/05/2013).

Turismo en Castilla y León. Disponible en: http://www.turismocastillayleon.com/cm/turcyl/tkContent?pgseed=1371157325 741\&idContent=91\&locale=es ES\&textOnly=false. Fecha de consulta $(10 / 05 / 2013)$.

Vachiano, M. \& Ramón, J. (2013). Turismo y Vino en la literatura académica: breve revisión bibliográfica. REDMARKA, 2(6), 55-82. www.cienciared.com.ar/ra/doc.php? $n=1800$

Vázquez De Miranda, H. (2012). Ruta do Viño Rías Baixas: Análisis desde el punto de vista de la oferta. Trabajo Fin de Grado. Dirigido por J. Álvarez García. Fac. de CC. Empresariais e Turismo. Disponible para consulta en sala: http://www.perseo.biblioteca.uvigo.es/search*gag/?searchtype=X\&searchscop $\mathrm{e}=3 \&$ searcharg=Ruta+do+Vi\%F10+R\%EDas+Baixas+an\%E1lisis+desde+el+p unto+de+vista+de+la+oferta\&SORT $=\mathrm{D}$

Vinos de España: Regulación. Disponible en: http://www.winesfromspain.com/icex/cda/controller/pageGen/0,3346,1559872 67633676778152 0,00.html. Fecha de consulta: (14/05/2013). 